This PDF is a selection from an out-of-print volume from the National Bureau of Economic Research

Volume Title: The Rate and Direction of Inventive Activity: Economic and Social Factors

Volume Author/Editor: Universities-National Bureau Committee for Economic Research, Committee on Economic Growth of the Social Science Research Council

Volume Publisher: Princeton University Press

Volume ISBN: 0-87014-304-2

Volume URL: http://www.nber.org/books/univ62-1

Publication Date: 1962

Chapter Title: Scientific Discovery and the Rate of Invention

Chapter Author: Irving Siegel

Chapter URL: http://www.nber.org/chapters/c2136

Chapter pages in book: (p. 441 - 458) 


\title{
Scientific Discovery and the Rate of Invention
}

\author{
IRVING H. SIEGEL \\ THE PATENT, TRADEMARK, AND COPYRIGHT FOUNDATION OF \\ GEORGE WASHINGTON UNIVERSITY AND THE U.S. COUNCIL OF \\ ECONOMIC ADVISERS
}

THIS paper discusses relations between scientific discovery and invention considered as concepts and as phenomena. The two entities are connected, as symbols and as realities, with the generation, treatment, and use of information, which is increasingly being recognized as a fundamental economic and technological "stuff" comparable to matter and energy. They enter into the logical sequences of ideas and events that culminate in the economic exploitation of new material and nonmaterial inputs, production methods, and products. In the contemporary setting, they represent typical goals of formal research and development projects, on which billions of dollars of public and private funds are being spent annually in the United States. They provide opportunities and avenues for cultural change, including economic growth and progress (which may be measured in terms of per capita real income and real output per man-hour, respectively); and they influence, although they cannot alone determine, the pace and directions of such change.

\section{Concepts of Scientific Discovery and Invention}

The terms scientific discovery and invention signify both acts and results of acts, both processes and outcomes. When used in plural form, they clearly refer to outcomes rather than processes; and when the singular form is preceded by the indefinite article, an outcome is connoted. Although in legal and other literature the terms discovery and invention are often coupled and treated as equivalent, they are assigned different meanings here. A distinction is intended even when, for the sake of simplicity, the adjective scientific is omitted. Discovery is the act of wresting a secret from nature; and a secret that is won is

Note: A full revised version of this report appears in the Patent, Trademark, and Copyright Journal, Fall 1960, under the title "Scientific Discovery, Invention, and the Cultural Environment." 
a discovery. More specifically, a discovery may be a "new" fact, principle, hypothesis, theory, or law concerning natural (including human) phenomena that are observable directly or through their effects. Novelty is to be determined from the standpoint of a nation or a civilization rather than from the viewpoint of an individual; what is new to a person other than the recognized pioneer may represent a rediscovery or just the diffusion of existing knowledge. Nevertheless, the "first" discoverer is not always accorded as much honor, if his name is remembered at all, as a later discoverer whose work has borne more fruit. Every discoverer actually builds upon a foundation of "old" knowledge that has become part of the cultural heritage, and the acknowledgement of his contribution depends on the manner in which he presents his findings and on the ripeness of his time. ${ }^{1}$ Too much primacy may be dismissed, in retrospect, as prematurity.

Invention may be regarded as purposeful and practical contriving based on existing knowledge (theoretical and applied) and uncommon insight or skill; that is, as the act of bringing to workable condition a potentially economic or usable process or product (an invention) that has a significantly novel feature. Again, tradition is relevant, and novelty is supposed to be judged from the standpoint of a nation (e.g., according to the standards of a patent system) or a civilization (e.g., against the background of all "prior art"); and, again, honor for primacy may be bestowed without a fine regard for historical literalness or the sensibilities of disgruntled inventors. Patriotism, insularity, indifference to exact definitions and specific patent claims, or ignorance may encourage attribution of an invention to a citizen of one country instead of another. But a preference in favor of native inventors may also reflect the fact that an invention has a cultural context, that it tends to be credited on the basis of its local development and significance rather than its abstract availability.

\footnotetext{
1 To avoid repetition of the "classic" cases of men of science against the world, I mention three great young chemists who even defied their own professors: van't Hoff and Arrhenius, who had the good fortune to enlist the aid of an Ostwald, and Couper, whose humbling by Wurtz left Kekulé to bask alone in glory. See Bernard Jaffe, Crucibles: The Story of Chemistry, Premier reprint, 1957, pp. 140-154; P. Cook, "The End of Chemistry Is Its Theory," Science News, October 1959, pp. 33-48; and Eduard Farber, The Evolution of Chemistry, New York, Ronald, 1952, pp. 164-166, 174-175, 222-225, 265-268.

Two other infrequently cited instances of professionally resisted advance come to mind-the insightful, though unrigorous, applications of mathematics to electrical engineering by Oliver Heaviside (inventor of the "operational calculus") and Gabriel Kron (pioneer in the analysis of stationary electrical networks and rotating electrical systems by means of matrices and tensors). Once accepted, the contributions of these two men proved valuable in mechanical engineering and more remote fields.
} 


\section{On "Rates" of Discovery and Invention}

Since events are more discrete than the acts that lead to them, the volume of scientific or inventive activity during any period of time is not perfectly correlated with the number of discoveries or inventions completed in the same interval. This divergence, however, is only one of many factors that should discourage a quantitative interpretation of the phrase "rate of invention" included in the title assigned to the present paper.

A much more relevant factor is the wide variation in the quality and significance of discoveries and inventions (considered as events), for a simple count of such events provides no clue to the number of "units" of significant novelty involved. As already noted, every scientist or inventor actually enters in medias res, from the standpoint of his culture, even though he may think he starts $a b$ ovo. A scientist may either add a small increment to the fund of knowledge or propose or effect a grand reorganization or synthesis; he may show either unusual persistence or genuine creativity, deftness of hand or incisiveness of mind, a tolerance of perspiration or a touch of inspiration. ${ }^{2}$ Happy accidents may befall some prepared minds and shorten the path to success or provide new goals, ${ }^{3}$ while mischance may frustrate others no less deserving. Once a pioneer is acknowledged, his work tends to resist depreciation as successors offer more elegant solutions of the same problems on the basis of newer knowledge. ${ }^{4}$ A hero may also be overcredited by common opinion with the achievements of his

\footnotetext{
${ }^{2}$ What weights would be appropriate for combining in one measure these three major qualitatively different achievements involving the speed of light: Michelson's painstaking measurement of this constant, Lorentz's use of th is speed as a limit in his "transformation equations" relating to the mass and length of moving objects, Einstein's use of it in his expression for converting mass into energy? Once Mendelejeff's periodic table of the chemical elements becomes established, should a new significance be attached to such ridiculed anticipations as Newlands' "law of octaves"? Is Fermi's calculation of the neutrino into existence a comparable feat to Maxwell's insistence on a mathematical symmetry that led beyond Ampère to the electromagnetic theory?

${ }^{3}$ On the role of accident, see I. B. Cohen, Science, Servant of Man, Boston, Little, Brown, 1948, pp. 36-50, 107-108; and W. I. B. Beveridge, Art of Scientific Investigation, Modern Library paperback, 1957, pp. 37-55. Also of interest is Ernst Mach's 1895 essay on "The Part Played by Accident in Invention and Discovery," published in his Popular Scientific Lectures, La Salle, Ill., Open Court, 1943, Sth ed., pp. 259-281. Of course, recognition of the role of chance may be traced back to much earlier observers (e.g., Francis Bacon).

4 Michelson's mechanical determinations of the velocity of light, refined over a halfcentury, were inherently much less accurate than the measurements subsequently made by many little-known workers in Federal laboratories using radar, radio waves, molecular vibrations, and "atomic clocks."
} 
predecessors, colleagues, and assistants $;^{5}$ and his true accomplishment may be ungenerously appraised by his peers or by members of a different profession. ${ }^{6}$ In an age of sophisticated formal research activity, it is easy to ridicule the empiricism of a Goodyear-and fail to recognize persisting elements in the testing of catalysts or medicines, in the minor modification of drug molecules, and in the screening of molds for antibiotics. Finally, the march of history may confer new significance on a discovery or invention thought to be minor or trivial in an earlier context.?

Other papers presented at this Conference deal with problems of measuring the rate of invention, so it is not necessary to discuss here the inadequacies of patent statistics, the uneven economic import of patented inventions, and similar matters. Three pertinent facts that have struck the author in the course of his work with the Patent, Trademark, and Copyright Foundation are: the wide neglect of patent "claims" as units of registered inventions; the manifold uncertainties still surrounding the legal concept of invention; and the necessity for somehow taking account of reinventions, trade secrets, know-how, and employee suggestions in the consideration of the universe of inventive activity.

\section{Discovery and Invention Seen in a Broader Context}

Modern circumstances require that increasing attention be given to the roles of discovery and invention in economic and other cultural change, and that more explicit consideration be given to these two

${ }^{5}$ This is true not only of broad syntheses such as Newton's or Einstein's but also of limited projects involving team research-e.g. the production of transuranium elements. The reader may find it instructive to check the names he recognizes in the list of credits shown for elements 98-101 by Albert Ghiorso and G. T. Seaborg, "Synthetic Elements: II," in New Chemistry, New York, Simon and Schuster, 1957, p. 137.

${ }^{6}$ Recall the attitude of physicists like Maxwell and Rowland toward inventors of practical things as simple as the telephone (Cohen, op. cit., pp. 61-63). Much more recently, sociologists and anthropologists have espoused cultural theories of invention and discovery that minimize the role of the individual. A prominent anthropologist, L. A. White (Science of Culture, New York, Grove reprint, pp. 213-214), has stated that Urey's isolation of heavy hydrogen (a feat winning the Nobel prize) did not require "intelligence of a high order" although it did demand more technological knowledge than the more familiar feat of "opening a recalcitrant jar of pickles."

- The Seebeck, Peltier, piezoelectric, magnetostrictive, and Edison effects are among the many discoveries that have acquired importance through time. Swan's artificial-fiber filament was not good for an incandescent light, but it pointed the way to rayon. Goddard's early work in rocketry and Jansky's discovery of radio-wave emanations from distant stars acquire increasing significance as our government gives urgent support to space science and technology. Patents on stereophonic recording expired before popular interest in an alternative to monaural disks was awakened. 
categories (or the activities they embrace) in the economic treatment of information. Among the relevant circumstances are: the multiplication and enlargement of corporate research programs; the annual outlay of billions of public dollars for private contract research; the clarification of accounting rules (e.g. in the Internal Revenue Code of 1954) regarding the treatment of private research costs; the increasing importance of the scientific and technological dimensions of national defense; the private acquisition of commercially valuable patents and experience through military contracts and subcontracts; the extensive exchange of technical information through intercompany arrangements and trade literature; the constant efforts to restrain domestic production costs (through process improvements) and to expand the horizons of domestic consumption (through introduction of new, acceptably-priced products); the intensifying competition with foreign industry for markets at home and abroad; the depletion of high-grade domestic mineral deposits; and the impressive advance in information-handling technology (e.g., electronic communications and data processing).

The new circumstances require, for example, a breakdown of the Schumpeterian triple sequence (invention, innovation, and imitation) into more stages and the interpolation of others. They also demand the establishment of subdivisions in the categories basic research, applied research, and development - to distinguish educational activities (which typically involve rediscovery and reinvention) from those that lead to discovery, invention, and innovation. Furthermore, they suggest the need for separate treatment of discovery and invention in sociological and anthropological theories, rather than their grouping as "new combinations and syntheses of cultural elements" that have a "platonic" existence and seem merely to await realization through the performance of minor acts of human catalysis; the recognition of sources, as well as effects, of scientific and technological advance; the recognition that discovery and invention interact; and re-examination of the functionality of the concept of cultural lag.

Finally, it is important in the contemporary setting to recognize not only the relation of discovery to basic research, or of invention to applied research and development, but also the relation of all these activities to operations involving information. As information takes its place beside matter and energy in the economic cosmogony, a spectrum of operations such as the following deserves attention: 
1. Creation of absolute information ${ }^{8}$ (discovery)

2. Processing

a. Screening and correlation

b. Reorganization and preliminary adaptation

c. Coding and decoding

d. Computing and logical analysis

e. Abstracting and digesting

f. Translation

g. Recording and indexing

h. Copying (as in printing, typing, or photography)

3. Storage, maintenance, and retrieval

4. Distribution and acquisition (as in radio and television broadcasting, interoffice communication, consultation, patent sale or licensing, and education)

5. Application

a. Embodiment in hypotheses and theories (discovery), invention, reinvention, and know-how

b. Utilization of invention, etc.

c. Decision making

All of these unitary activities create time, place, form, or ownership utility; they are services that command a price. They may be expanded and regrouped to take account of the schemes used by Schumpeter, Usher, Maclaurin, and others. Analogues exist at various levels of aggregation-for example, the occupation, the department, the firm, the industry, the economy.

Analogues also appear at the various levels of biological existence, from the individual down to the cell, chromosome, and gene; and this fact will assume increasing importance in the study of creative and other behavior, life processes, and heredity. From an economic appreciation of material substance, including fuels, man has naturally progressed to an appreciation of energy in more abstract terms. Today, we are witnessing the emergence of information as an economic stuff with the recognition of the special value of energy signals in communication. The stage is also being set, through advances in the life

${ }^{8}$ A term used by L. Brillouin, "Thermodynamics and Information Theory," American Scientist, October 1950, pp. 594-599.

Alternatives to, or extensions of, the catalogue presented here will be suggested by a rapidly growing literature. See, for example, J. D. Trimmer, "The Basis for a Science of Instrumentology", Science, October 23, 1953, pp. 46I-465; and papers by J. P. Guilford and J. S. Bruner in Fundamentals of Psychology: The Psychology of Thinking (Annals of the New York Academy of Sciences, Vol. 91, Art. 1, December 23, 1960, pp. 6-21 and 23-37. 
sciences, for the identification of "vitality" as a fourth entity. The distinction will seem valid and desirable even though material, energy, and information processes underlie all manifestations of life. Examples of pertinent advances include, in addition to those already familiar in agriculture and medicine, the successful "imprinting" of animal behavior in early life, the treatment of viruses as living molecules, the increasing understanding of the role of specialized organs and molecules (such as adenosine triphosphate) in the biological "transduction" of energy, the recognition of the importance of intercellular communication for "homeostasis," and the awareness that intracellular communication via "replicating" nucleic acid molecules plays an outstanding part in specifying the inheritable features of a future adult organism.

\section{Sequences and Interactions}

It should be mentioned in passing that the private costs of acquiring new knowledge and giving up old knowledge would limit the practical force of the proposition that the marginal social cost of using an invention is zero. Even if no royalties had to be paid for patent licenses and the flow of new inventions could still be assured, potential users would still have to learn of the existence, technical nature, and economic applicability of the free inventions. They would also have to be willing to abandon knowledge and skills they already possess. In other words, costs of change (beyond the costs of reforming society so that the theorems of welfare economics would become more acceptable!) have to be taken into account.

Single-factor theories of development are attractive, but the assumption of interaction among the leading entities often provides a sounder first approximation than does linear causation in one direction. In considering the roles of discovery and invention in the real world, it is desirable not to preclude the possibility of their interdependence and their influence on, as well as their reaction to, economic, social (including political, legal, and familial), psychological, and international factors. The firm adoption of a theory of determinismgeographic, biological, or cultural-would hobble inquiry or, if we are more fortunate, lead to hypotheses that could quickly be contradicted. ${ }^{9}$

Although discovery logically precedes invention, experience indicates that the reverse order also occurs to the extent that an invention has considerable practical importance. Thus, the invention of all 
sorts of instruments and apparatus has proved essential to the progress of science. Behind these instruments, of course, lie other discoveries, but the tools of industry and the skills of workers and the vast store of accumulated technological information should not be overlooked. As we think further about such interrelations, the integrity of a modern society becomes obvious.

Sometimes, the heart of a scientific discovery is actually a physical invention or a mental invention, in which instances we may well say that discovery and invention proceed together. Thus, in the very broad territory covered by military research nowadays, a genuine scientific advance may be immediately reducible to practice and lead to a patent for a process or composition of matter. On the other hand, a scientific discovery that involves explanation rather than, or in addition to, observation may require the invention of convenient mental fictions-concepts or models-or entail the invention or reinvention of a type of (unpatentable) mathematics.

Although we are culturally conditioned to believe that technology is autonomous, that it follows a relentless if unpredictable course, that it molds almost everything else, we may easily verify that the arrows of influence also point in the opposite direction, as in many chemical equations. Thus, economic considerations affect the technological future, as is so well illustrated by the lag of nuclear power generation, despite flamboyant forecasts, and the widening use of by-product radioisotopes. The profitability of atomic power stations is still in doubt, despite the willingness of society to forego the recovery of billions of dollars of past investment in nuclear science and technology; conventional steam stations based on coal retain their competitive vigor, benefiting still from applications of "old-fashioned" knowledge.

Another factor that helps shape technology is military necessity,

"Cohen (op. cit.) properly stresses the importance of the "total scientific situation" in influencing the course of discovery and invention; and E. G. Boring, the psychologist, properly observes that the Zeitgeist may in some cases advance and in others hold back scientific and technological change, and that our knowledge of pertinent facts is always inadequate for correct prognostication ("Science and the Meaning of Its History," The Key Reporter, July 1959, pp. 2-3).

On interaction and forecasting, see also Bernard Barber, Science and the Social Order, Glencoe, Free Press, 1952, and four papers by I. H. Siegel: "Technological Change and Long-Run Forecasting," Journal of Business, July 1953, pp. 141-156; "Conditions of American Technological Progress," American Economic Review, May 1954, pp. 161-177; "The Role of Scientific Research in Stimulating Economic Progress," ibid., May 1954, pp. 340-345; and "Changing Technology and Resources," presented at the Conference on Natural Resources and Economic Growth, Ann Arbor, April 7-9, 1960. 
which now dictates, for example, the abandonment of manned aircraft for missiles in response to a foreign initiative. Firms are counting on the development of commercial supersonic liners at huge public expense; the prototype bomber (B-70) is regarded as essential for defense and national prestige. In the past, military necessity, plus a timely declassification, permitted the apparently profitable development and introduction of commercial jet airplanes despite the inadequacy of existing airports and the absence of helicopter shuttle service.

Finally, we should note the vigor of the foreign bid for a share in United States markets as an emerging influence on our technology. This challenge has brought back the domestic compact car, has probably speeded the domestic development of transistorized radio and television receivers, and will hasten the diffusion of steelmaking methods employing large amounts of oxygen. The adjustment of complementary research efforts of our firms will surely lead to new discoveries and inventions in the same and other general fields.

\section{Interplay of New and Old Science and Technology}

As future directions of change and growth are contemplated, it is important to recognize that considerable room still exists for discovery, invention, innovation, and investment in fields already familiar as well as in frontier areas. The advance into such new areas stimulates certain established technologies and provides new contexts for the revaluation and upgrading of old knowledge. The advent of atomic energy has already raised the national base of conventionally generated electric power and increased the demand for lead, steel, concrete, water, automobile transportation, and so forth; it has not simply created an interest in beryllium, zirconium, hafnium, the rare earths, uranium, thorium, and other comparatively exotic materials.

Even without speculating on the nature of future developments that will enrich existing science and invention, we may observe the reassuring pattern in recent years of the cross-fertilization of the old and the new. It is as though we could find space for new people by filling gaps between our cities rather than, say, by having to settle at once on Antarctica, a moon, or other planets. Consider the rising interest, in the present context, not only in atomic and solar energy and magneto-hydrodynamics but also in power technologies originating in the nineteenth century-the fuel cell (derived from Faraday), the thermocouple, and thermionics. Consider the startling discovery 
of a new color theory by Land that follows up neglected hints in patents granted to two men in 1914, overthrows the classical theory of Newton, Young, and Helmholtz, and is bound to simplify color photography. ${ }^{10}$ Finally, the limited but significant revolt of the public against industry control of its taste in automobiles is sure to encourage broader competitive experimentation by makers with materials and power plants already known but used rarely or not at all." Continuing suburbanization, expansion of tourism, further population growth, rising demands for education and health services, and the automatization of industry are more likely to occasion difficult adjustments of a familiar variety (such as location of responsibility for adequate capital formation, taxation, and welfare legislation) than to require sudden diversification of the nation's existing base of science and invention. In the military realm, however, where the pattern of competition and the timetable are not controlled by one nation, crash programs of one kind or another may continue to be required for national safety. ${ }^{12}$

\section{COMMENT}

\section{Thомas S. KunN, University of California}

One aspect of Irving Siegel's paper seems to me particularly striking, at least in the full version distributed to conference participants. Unlike more standard discussions of similar problems, Siegel rejects from the start all the usual simplifying schematic assumptions. From start to finish the author displays no fear of the full complexities of the job at hand, and, since a willingness to face difficulties seems an admirable characteristic, I can only admire and applaud his courage. My admiration is particularly warm because of my firm

${ }^{10}$ Francis Bello, “An Astonishing New Theory of Color," Fortune, May 1959, pp. $144 \mathrm{ff}$.

"See, for example, the article by Damon Stetson in the New York Times, March 14, 1960. Incidentally, the General Motors Annual Report for 1959 notes (p. 12) that the Stirling thermal engine is under study: "New developments in material and design have revived interest in this 19th Century engine, noted for quietness and ability to burn wide variety of fuels."

12 In a comment made in Capital Formation and Economic Growth, Princeton, 1955, pp. 572-578, I. H. Siegel noted that technological change occurs almost continually and almost everywhere in our economy, even though only the dramatic instances are usually singled out for attention; that the technical growing points of our economy should accordingly be sought in the activities and demands of (1) the household, (2) private industry, (3) government, and (4) other nations seeking trade or aid; and that Colin Clark's triple classification scheme should accordingly be altered to include these four additional categories from which new industries or subindustries arise. 
conviction that all the difficulties to which Siegel points are entirely real. He is obviously, for example, quite right when he insists that neither patent counting nor national reputation is an adequate measure of a country's eminence in invention. Again, he must be right in his insistence that Schumpeter's triple sequence-invention, innovation, and imitation-is no longer adequate for the analysis of technological change, and that the analyst must now investigate a full spectrum of sequential activities. By the same token, I can only agree when Siegel does battle with all "single-factor" accounts of inventive and innovating activities. Furthermore, his sketch of the multiple factors-social, economic, psychological, and so on-whose interactions must be taken into account, seems to me eminently just. And these are only illustrations of the analytic difficulties to which Siegel points. In almost every other case as well I find myself in complete agreement.

Those remarks might, by themselves, serve as a full commentary on Siegel's paper, but I sense something else that must be said. The topic to which his title directs our attention is the relation of scientific discovery to inventive activity. That topic has urgent action corollaries for both national and industrial policy. Given such a problem, the multiplication of complexities-even, as in this case, real onesneed not necessarily supply the most fruitful approach to a solution. From my own experience, it seldom supplies the most fruitful approach to even the "purest" of scientific problems. These reflections lead me to voice a small but persistent fear that Siegel, in his admirable concern to face squarely the real complexities of the contemporary scene, may have succeeded principally in disguising the most important problem that, to me at least, his subject presents. In what follows I shall limit myself to the elucidation of that fear.

Unfortunately I am forced to begin with a terminological problem. Siegel uses the words "discovery" and "invention" in ways with which I have little quarrel but which are so far from my habitual professional usage that an attempt on my part to follow him is likely to create only confusion and obscurity. In his paper, invention is "purposeful and practical contriving based on existing knowledge"; for the corresponding spectrum of activities I shall use the terms technology, applied science, and, perhaps, engineering. Again, and more significantly, Siegel uses discovery to mean "a new fact, principle, ... theory, or law"; for the activities that produce these results I shall employ the term science or, more appropriately, basic science. This 
change of terms will enable me to describe my worry in clearer and more familiar ways. ${ }^{1}$

Midway through his paper Siegel suggests that perhaps sociologists and anthropologists should adopt different treatments when analyzing discovery, on the one hand, and invention, on the other. (This differentiation corresponds to mine between science and technology.) But, except at this point and in his introductory definitions, Siegel scarcely employs separate treatments himself. On the contrary, his evidence is drawn indiscriminately from technology and science (most of it is, in fact, drawn from technology), and he concludes by deriving a single set of generalizations, explicitly applicable to both activities from this undifferentiated body of evidence. History of science provides grounds for grave doubts about both this procedure and the conclusions drawn from it. Furthermore, these doubts are unaffected by history's total failure to produce any definition that will invariably distinguish a scientific from a technological development. I am even dubious that such a definition could be given. There are too many historical episodes that lie squarely on the border and that would have to be described as neither science nor technology or as both. Nevertheless, it seems to me of first importance, in approaching Siegel's problem, to recognize that the two activities, science and technology, have very often been almost entirely distinct.

A few brief and vastly too simplified historical illustrations will clarify what I have in mind. In presenting them my object is at least to make plausible such generalizations as the following: until about a century ago science and technology most of ten flourished at different historical times; when, occasionally, they did flourish in the same period, they most often did so at different geographical locations. If these generalizations are even approximately correct (and in the nature of the case they cannot be more than that), they should at least suggest that historically science and technology have been relatively independent enterprises. ${ }^{2}$ And they may suggest somewhat more. The

\footnotetext{
${ }^{1}$ This terminological shift probably has little importance to the problem at hand, but it can be of critical significance in the analysis, historical or logical, of science and of technology. In my own field, for example, it is often important to remember that, while scientists may discover new objects or phenomena, they must invent new theories. By the same token, one would distrust an analysis of technology which prohibited the inventor from discovering anything at all. At a higher philosophical level, of course, the distinction once again becomes problematic, but it still seems a necessary starting point.

"To use the word "independence" I have to neglect the very important stimulus which developments in technology and the crafts have repeatedly provided to the sciences since the beginning of recorded history. That stimulus is extremely important to the historian of
} 
cultural matrix that has supported a flourishing scientific enterprise has not usually supported a progressive technology and vice versa. At least part of the historical pattern I shall sketch thus hints at an actual conflict between the two enterprises. I remind you, for example, that, excluding the last few decades about which no secure judgment is yet possible, the only nation that has achieved simultaneous eminence in both science and technology is Germany in the years from about 1860 to 1930 .

Let me then throw the historian's usual caution to the winds (it proves remarkably difficult to do) and omit all qualifications. I suggest to you, first, that the greatest achievements of ancient technology are largely restricted to the period before 700 B.C., and that the major development of science comes almost entirely after that date. Again, it seems noteworthy that ancient science, when it did develop, was largely Greek but that Greece was technologically a debtor nation. The great technological power of classical antiquity was Rome, and the Romans made little use of Greek science and developed none of their own. That pattern of the separate locus of science and technology continues into modern times. The technological changes that helped to bring the Middle Ages to a close and that ushered in the Renaissance were almost completed by 1500 . But the scientific discoveries that collectively constitute the Scientific Revolution were produced almost entirely after that date. Or, we may move into still more recent times and examine the situation at the very start of the nineteenth century. At that time, Britain was at the height of the Industrial Revolution, the acknowledged leader of Europe in the production and exploitation of technological innovations. But, simultaneously, England was widely felt to be a relatively backward country scientifically. At the beginning of the nineteenth century it was technologically backward France that led Europe in the sciences and that was universally acknowledged to do so. ${ }^{3}$

These are the sort of contrasts that lead me to urge the desirability, at least in a first approximation, of considering science and technology as separate enterprises and very likely in some conflict one with the other. I hasten to add, however, that the historian can delin-

science, but it has little bearing on the question here at issue. We are looking for an influence of scientific discovery and invention upon technology, and that seems to have been very nearly negligible before the nineteenth century.

${ }^{3}$ For an excellent and somewhat more extended account of much of the material in this paragraph, see R. P. Multhauf, "The Scientist and the 'Improver' of Technology," Technology and Culture, 1959, pp. 38-47. 
eate this independence only by restricting attention to the period before 1860 . Before that date, the facts and theories discovered and invented by scientists contributed little to progress in technological innovation. ${ }^{4}$ Despite persistent rumors to the contrary, neither the Greeks, nor Galileo and Newton, nor even Black and Lavoisier taught the great technological innovators very much of what they needed to know about nature. Astronomy, dynamics, and inorganic chemistry - the principal fields in which these famous men made their most notable contributions-did not prove very relevant to major technological advances. Only with the development of the electric battery and of organic chemistry did science begin to achieve largescale success in fields that promised direct and relatively rapid application. But these are nineteenth-century fields, and their exploitation had scarcely begun before the middle of the century. Once it did begin the whole pattern of relationships between science and technology changed rapidly and drastically.

Today that change is familiar to all. Since 1860 a number of industries have been revolutionized and many others have been brought into being by a massive influx of information and techniques from the basic scientific laboratory. In these industries one finds that characteristic twentieth-century institution, the industrial research laboratory, and in these laboratories one finds that characteristic twentieth-century figure, the new innovator-engineer whose satisfactory performance demands much basic scientific training. In any society where industries like these bulk large even the old approximate independence of science and technology is very hard to find. In our

\footnotetext{
4 Note that I speak of the effect upon technology of scientific discovery and invention. If we were concerned instead with the effect of scientific method or of the scientific attitude upon technology, we would find that it became significant at least a century earlier. The need for this distinction between the effects of scientific method and those of scientific results is too seldom noted, and the consequence is a considerable confusion in the literature. See, for example, the two excellent papers by C. C. Gillispie and R. E. Schofield (Isis, 1957, pp. 398-415). Because one of these authors sees science as method, the other as accumulated fact and theory, their papers reach opposite conclusions about the relation of science and technology in the late eighteenth century from facts that both are quite willing to grant. The same confusion shows again and again elsewhere and can be at least partially dispelled by the same technique. For example, Smeaton's improvements of the Newcomen engine did not depend significantly upon prior scientific knowledge and Watt's may not have done so. But both these men, unlike the innovators in, say, the eighteenth-century textile industry, arrived at their improvements by the same sorts of laboratory techniques that their contemporaries were employing in the sciences. In the same period the same sort of methodological borrowing is also apparent in the inorganic chemical industry (see Henry Guerlac, "Some French Antecedents of the Chemical Revolution," Chymia, 1958, pp. 73-112).
} 
day the two enterprises are intimately entangled as they have never been before.

Nevertheless, I see no reason to suppose that the entanglements, which have evolved during the last hundred years, have at all done away with the differences between the scientific and technological enterprises or with their potential conflicts. A casual scrutiny of either the congressional debates and hearings on the National Science Foundation or of the editorials in the journal, Science, strongly suggests that these differences and conflicts are an integral part of contemporary life. The evidence I have tried to draw from MacKinnon's paper points in the same direction, and there is biographical evidence to the same effect, besides. I think, for example, of Edison's famous statement to his chief engineer: "We can't be like the old German professor who as long as he can get his black bread and beer is content to spend his whole life studying the fuzz on a bee!" That was the closing line in a devastating critique of one of the Ph.D.'s employed at Menlo Park, a man who, according to Edison, constantly got sidetracked and lost time because he insisted upon following up phenomena that were new to him. ${ }^{5} \mathrm{Or}$, note what has happened to the triumvirate whose successful development of the transistor Richard Nelson has so well described for this conference. Only one of the three is still at Bell Laboratories; a second has now started his own industrial concern; and the third has joined the staff of a major university. Instances like these, reflecting the rather different goals and drives of the scientist and the technologist, can be multiplied ad nauseam. That being the case, it seems a great shortcoming in any paper on the relations of science and invention that it should do so very little to reflect their existence.

Let me close therefore by pointing to just two effects upon Siegel's paper of this failure to discriminate. I begin by considering the "spectrum of operations" which he outlines. To the extent that I understand the terms employed, I think that spectrum-from discovery, through processing, to application-fits applied science well enough. But, though scientists do many of the same things, I have great difficulty fitting the same spectrum to their enterprise. In part the implied order of operations seems wrong. More important, I can discover far too little place for the sorts of problem solving that scientists most characteristically undertake. Furthermore, I doubt

\footnotetext{
5 H. C. Passer, The Electrical Manufacturers, 1875-1900, Cambridge, Mass., 1953, pp. $180-181$.
} 
that a few changes of phrase and the addition of new items to Siegel's list would much relieve my difficulties. On the contrary, a schema of a fundamentally different form seems to be needed. Instead of a single spectrum, consider two parallel ones, descending from a common pool labeled. "Existing Knowledge." One of these parallel lines is to represent science, the other, technology, and their possession of a common origin indicates that both the scientist and the inventorengineer depend for the source and structure of their enterprises upon what is already known.

This schema is obviously only a beginning, and in some respects it may be a misleading one. (Today, as I have already indicated, science and technology are by no means so clearly separate as the schema up to this point implies.) But the double spectrum has obvious advantages over the single one, among them, that it provides a basis for discussion of Siegel's topic, the interaction between science and technology or between science and inventive activity. The most obvious channel for interactions is through the pool of existing knowledge, from which both enterprises begin and to which both feed back. In the sorts of industries studied by Jacob Schmookler-agriculture, the paper industry, and railroads - it has probably provided the only significant channel. Like technology at large before 1860 , these industries have profited only from past scientific achievements and not very often even from those. But the pool of existing knowledge does not provide the only channel for interaction or the only one illustrated in modern industry. Nelson's case history of the transistor shows that at least occasionally and temporarily the problems of the basic scientist and of the technologist can be the same. Identical overlaps could, I feel sure, be shown to occur even more frequently in the organic chemical industries, though even there they would probably not bulk very large. But they do occur, and my schematic revision of Siegel's spectrum therefore needs to be supplemented by a series of double headed arrows connecting the "science" line with the "technology" line at various distances from their common origin.

These remarks prepare the way for my second and concluding illustrative remark about the effect of failure to discriminate upon Siegel's paper. If one sees in the contemporary scientific-technological scene not a single enterprise, but two in constant interaction, then one may be prepared to discover that the social, economic, and psychological factors that Siegel so properly emphasizes have quite different effects upon the two. And if one has gone that far, then one may hesitate 
to conclude, as Siegel does, that "the base of science already appears sufficiently large and diversified ... to accommodate as much growth as other factors in the environment will demand and allow." That statement may well be correct. But, since Siegel means by "science" the entire spectrum of activities from basic science through applied science to ingenious invention, there is no evidence for it in his paper. Perhaps he has proved his point for technology. One might also grant what he says about "the base of science." But one could do all this and still argue that the diversity of the contemporary scientific enterprise, as against that of contemporary technology, is neither so great as it has been nor as it should be. I shall not here argue that position, but I do regret that Siegel's paper does so much to prevent the questions that underlie it from even being asked. 
